\title{
Network structure and user roles of a crowdsourcing community - The context of social innovations for a development project
}

\author{
Simon Fuger \\ University of Innsbruck \\ simon.fuger@uibk.ac.at
}

\author{
Robert Schimpf \\ University of Innsbruck \\ robert.schimpf@uibk.ac.at
}

\author{
Johann Füller \\ University of Innsbruck \\ johann.fueller@uibk.ac.at
}

\author{
Katja Hutter \\ University of Salzburg \\ katja.hutter@sbg.ac.at
}

\begin{abstract}
The principles of crowdsourcing are increasingly applied in social contexts like development projects. In this study we explore a crowdsourcing community, which aims to enhance conditions in low income communities. We investigate the network structures of the community and detect behavioral pattern and user roles based on participation behavior for this specific context. Overall, the observed community shows a high level of collaboration and reciprocal dialogue. On the individual level we located four different user roles distinct in their interaction and contribution behavior. So called "collaborators" are considered as unique user role in an online community within a social context. We contribute to the theory of crowdsourcing by illustrating that context and purpose of crowdsourcing initiatives may influence the behavioral pattern of users. Further we add insights to the junctures between crowdsourcing and social innovation in the context of open development.
\end{abstract}

\section{Introduction}

Today, the world is facing major challenges such as economic crisis, climate change, the poverty in developing countries and the aging of society. Finding creative solutions to social problems is therefore of rising importance and social innovations are required. Social innovations emanate from all sectors and levels of society and somehow impact the lives of several people on earth [1]. Particularly in low-income communities, such innovations are indeed called for to influence social change. The successes of open innovation in the business world [2] and the power of the crowd [3] have inspired scholars to consider integrating crowd-based communities to foster social innovation [4] and open development processes [5]. As evidenced by extant research, crowdsourcing has great potential to establish communities and produce social innovations [6]. As such complex problems may be addressed through discussions by engaged users who share their ideas and/or experiences concerning new pertinent developments [7]. Decentralized collaboration and sharing engages more individuals enabling the collective search for initiatives and solutions that touch the lives of masses positively and meaningfully [5]; although attracting motivated participants necessitates a meaningful topic and dialogue to induce their engagement and interaction [8].

Research to elaborate structures that enable ideation for social change [9], and the dynamics of ICT mediated development projects [10] is plausibly desirable, yet investigation into the application of crowdsourcing principles for social innovation particularly in the context of open development projects seems scarce.

Literature suggests that in order to successfully manage crowdsourcing communities, an understanding of different user roles and behaviors (e.g. contributions, knowledge sharing and social interactions) within the community needs to be achieved [27]. Therefore the research question of this study explores the types of user behavior that can be found in a crowdsourcing initiative focusing on social innovations in the specific context of open development projects.

To gain an understanding about the underlying dynamics of online communities, various studies have investigated network structures and communities' user types based on participation and contribution behavior [1]. Such user behavior and user types might vary [1113], depending on the context and purpose of a community. In this sense, this research also contributes to literature by elaborating differences of behavioral patterns of users in the social context compared to existing research on crowdsourcing initiatives.

Overall this study examines the network structure, the heterogeneity of users and distinct user types for an initiative that uses a crowdsourcing approach to search for social innovation and improve the conditions of low income communities.

The remainder of this article is structured as follows: In Section 2 of this study, we introduce literature around the concept of social innovation and the shift to open models in international development. The principles of crowdsourcing are illustrated and the connection to social innovation is established, before the participation behavior of users and their roles within online 
communities are highlighted. Section 3 presents the investigated community and the applied methods. We present our findings in Section 4 , and conclude with a discussion and implications.

\section{Literature Review}

\subsection{Social Innovation}

Social innovations are innovations "[...] that are social both in their ends and in their means" [14](p.4). Phills et al. [15] refer to social innovation as "[...] a novel solution to a social problem that is more effective, efficient, sustainable, or just than existing solutions and for which the value created accrues primarily to society as a whole rather than private individuals" (p.36). Most social problems are of multifaceted nature and high difficulty [16, 17]. To come up with solutions, it is therefore important to gain deep insights into the cause of a societal problem [17], the environment and the affected people [17]. Literature agrees that cooperation across multi-stakeholder environments [17], collective action and aligned interests [18] to contribute to the public good and endorse change in the social system [9] are required to overcome challenges. Merging locals, sponsors, social entrepreneurs and other stakeholders and creating networks that lead to supportive communities is crucial [19]. Social entrepreneurs in this manner are agents of social innovation who follow social goals instead of sole personal interests [17]. They are instrumental for the enacting of social innovation [15], have tremendous intrinsic motivation to do social good and are driven by altruism [20].

Social innovation is required in all sectors and all levels of society [1]. Particularly relevant for the context of our study are applications for social innovation in the field of international development work (for low income communities).

\subsection{Crowdsourcing as a form of Open Development}

Literature suggests that to fully exploit socially innovative behavior and the potential value creation, 'open' models should be implemented, as it increases the effectiveness of developing innovations that address the roots of a societal problem [4]. Put differently, socially innovative organizations should include their broader network in their innovation processes. Similar to the broader social innovation literature, the research stream of international development has experienced a shift towards open models over the past five years [5]. Referred to as open development, the application of open models in international development describes the configurations of content and the process to bring people together [5] and improve the lives of people. Often these open models are accompanied by the inclusion of ICT [21].

Open models are described by numerous assumptions shaping the open space (e.g. participation process, communication between actors) [5]. Considered as a progression from ICT for development (ICT4D), open development is attributed to the ability to radically change the development landscape [21]. In this context, a decentralized collaboration and sharing knowledge in a crowd-based initiative is assumed to provide benefits to more people in more effective ways, in comparison to sole traditional practices [5].

People who contribute to open development are not driven by greed or competition. Instead they follow "intrinsic human needs to make useful and meaningful contributions, share openly and collaborate freely" [8](p.341), similar to the context of social innovation. The acknowledgment of others' human intentionality and a shared purpose might engender a meaningful dialogue and interaction among actors [8].

Open models are diverse in structure, context and outcome. Yet they commonly characterize human cooperation and permit openness by employing digital components. Open models enable the sharing of ideas, and the reuse and revision of content, they also increase the transparency of processes and foster participation and collaborative behavior [22].

Crowdsourcing [23] typifies an approach to open up a development process and foster social innovation. Generally, the term is defined as "[...] the act of taking a job traditionally performed by a designated agent (usually an employee) and outsourcing it to an undefined, generally large group of people in the form of an open call" [3](p.99). The basic assumption behind crowdsourcing refers to the notion of "the wisdom of the crowd" [24]. Wherein large groups that are working jointly are considered to create more knowledge and information and therefore intelligence that yield to a higher value compared to the work of individual users [24]. According to Boudreau and Lakhani [25] crowdsourcing initiatives can be organised as contests or communities, depending on the context and kind of a challenge. Most often these initiatives possess an online component. One disparity between contests and communities is the handling of contribution. While contests focus on the maximization of diverse contributions, communities anticipate a coherent and value-creating whole by aggregating various contributions [25]. Thereby free information sharing and the possibility to collect and combine ideas facilitate success for such initiatives [25].

Specifically, crowdsourcing initiatives for social innovation have adopted models from the private sector 
in various contexts, including design contests (e.g. ScrapLab Design Contest for upcycled products made of waste) [26]; collaborative communities (e.g. Travel2Change - a crowdsourcing platform that combines traveling with voluntary work) [26], or open source projects (e.g. HarassMap - an open source software platform for the geo-location of sexual harassment in Egypt) [21]. The focus in this study is on a collaborative community that aims to improve the conditions in low income communities. This is in light of the fact that, in our view, most crowdsourcing initiatives for social innovation are of collaborative nature, following the mutual goal to enhance the lives of people on the planet.

\subsection{User Roles in Crowdsourcing Communities}

Crowdsourcing initiatives often produce virtual communities distinct in their nature and structure. Previous studies provide important insights into the identification and conceptualization of different user roles in various online communities. As indicators of distinct user roles the frequency of participation and the volume of contribution were often used [12]. For instance, Kozinets [28] forms four user types (tourists, minglers, devotees, and insiders) in virtual communities of consumption, according to their relationships with and to the community. Since researchers have acknowledged the overlaps between networks and communities [12], social network analysis is a commonly applied method for investigating user roles in online communities [29]. In this vein, Koch et al. [30] revealed six user roles in an online community in a political context, namely motivators, attention attractors, idea generators, communicators, masters, and passive users. Also Füller et al. [31] identified six different user types (masters, socializers, idea generators, efficient contributors, passive idea generators and passive commentators) in innovation contest communities. Although the community includes a hybrid structure with cooperation and competition, the basic social structure of online communities is met [31]. Toral et al. [32] discovered the user type "brokers" in an open source project. Overall, the aforementioned user types are essential for the information flow within the community as they act, as intermediaries between experts and peripheral users.

The combination of the concepts social innovation and crowdsourcing is a rather new phenomenon, which has been investigated by only a small number of researchers [23], especially in the context of open development. We follow the research suggestion of Cajaiba-Santana [9] regarding the search for structures to enable agents to engage in the development of ideas that promote social change. It is argued that complex descriptions of social innovation processes and communities are needed in order to deliver new insights into a concept not yet explored in innovation literature [9].

Research is also required on the specific dynamics of new forms of ICT-mediated sharing, cooperation, participation, and collaboration in the context of open development [10]. It is frequently argued that the context and purpose of communities influences the type of users and their behaviors [11-13]. Further, the importance of a clear understanding of the underlying community network structure and the user roles is highlighted to successfully manage such online communities [11]. It seems crucial to study users' behavior in various settings and scenarios [33]. We are keen on exploring the heterogeneity of users and distinct user types of an initiative that uses the crowdsourcing approach to seek social innovation and improve the conditions of low income communities. In light of the literature drawn upon in this study, we expect high collaboration activities and close relations among participants, following the mutual goal of contributing and solving social challenges.

\section{Empirical Study}

\subsection{Data Collection}

Data was derived from the openIDEO platform. The community at openIDEO consists of more than 17.000 users from over 170 countries. The platform has already conducted over 30 challenges to foster social innovations in different fields. The community of openIDEO can be considered as a collaborative community [25]. OpenIDEO only provides the platform and its community and acts as a facilitator to the challenges. In this study, we analyzed a challenge hosted by the Amplify program, which was initiated by the UK Department for International Development (DFID). The goal of this program is to end extreme poverty in low income communities with the help of social innovations. The program runs 10 challenges over 5 years on the platform openIDEO. The challenge addressed in this study is focusing on the central question: "How might we make low-income urban areas safer and more empowering for women and girls?". The challenge is divided into successive phases with clear assignments of tasks in each phase. First, there was the "research phase" with the aim to motivate all participants to share inspirations, stories, tools and successful examples on the challenge topic. Based on these insights the "idea phase" followed and participants were asked to propose solutions to the given problem. Best ideas were then selected via an applause phase by 
the community and experts to advance to the "refinement phase" where the community collaboratively refined those ideas. An evaluation phase followed to select the final ideas with the view of having the most feasible ones funded.

The main part of the challenge was conducted within 22 weeks from February 2014 to July 2014. During this time period community members were able to comment and applaud research contributions and ideas. Furthermore they were able to build teams, work together on ideas, update their ideas, and write stories about the impact of their ideas.

In total, 4057 users followed the investigated Amplify Challenge whereby 7646 comments were written. Within the idea phase, 450 individuals submitted a total of 575 ideas, out of which 52 ideas were selected for the refinement phase, 15 ideas were awarded as "final ideas", from which 3 ideas received funding.

The data about the openIDEO Amplify challenge was retrieved from the platforms server log files that record every activity taking place on the website. A digital file was generated that includes all data available on the crowdsourcing initiative. Users were able to comment on ideas in every phase of the challenge. Each comment was assigned to a specific user ID which enabled this study to figure out exactly who a commenter was and who the receiver of the comment was.

\subsection{Research Methods}

We applied social network analysis (SNA) and network measures (in-degree, out-degree, betweenness, reciprocity) to visualize and interpret the network structure of the community. Based on individual user network measures and contribution quantity of users, we were able to conduct a cluster analysis and detect distinct user roles. In addition, we conducted an analysis of variance (ANOVA) to compare the quality of submitted ideas across the identified user roles and compare the structural position of these user roles.

Social network analysis: With the help of a social network analysis, the interaction between participants can be grasped. The Amplify Challenge \#1 can be considered to be a social network as actor to actor relationships exist based on comments written on ideas. While most sociological methods exclude the individual from context and therefore constrain to single actors in a network, the social network analysis allows a researcher to analyze whole social systems. The big advantage here is that social network analysis is able to focus on traditional analysis at an individual basis, and at the same time considering information about the relationship across network members including the social context [34]. Applying social network analysis enables the identification of different roles of the user of an online community, their distinct traits and influences on the whole community or other individuals [35] and their structural position in the community [36]. This type of analysis allowed us to calculate specific actor based network measures that describe the interaction behavior of users in the network. The software UCINET 6.556 was used to calculate all measures relating to social network analysis, and to visualize the presented sociograms.

Cluster Analysis: In a next step we applied a cluster analysis based on measures describing interaction and contribution behavior retrieved from SNA (in-degree and out-degree) and the number of contributions. This inductive technique helps develop empirical groupings of persons, which can then serve as a basis for further analysis [37]. Key properties of clusters are external isolation and internal cohesion [38]. External isolation means that objects in one cluster have to be in proper distance with objects of another cluster. Internal cohesion refers to the need of similarity of objects within the same cluster. In our case this method enabled the differentiation between different groups of actors which can be considered as grouping of user roles based on commenting and contribution behavior within the community.

\subsection{Measures of Interaction and Contribution Behavior}

In this study we decided to use the measures indegree, out-degree and contributions to conduct a cluster analysis. These measures were chosen to be able to compare the results to previously conducted research in online communities using the same measures to identify user roles, e.g. [12, 30, 31]. SNA represents a valuable method to identify user roles as the derived social network methods can be used as a practical diagnostic and monitoring tool for community behavior [11]. To gain a complex understanding of how users behave the measures were divided into two separate types of behavior.

Interaction Behavior: As users on the platform are able to either write comments or receive comments two different measures are used to capture commenting behavior, namely in-degree and out-degree. With the help of in-degree and out-degree centrality, popularity or activeness of a user can be determined [39]. In-degree is a measure that represents all ingoing relations of a user. Out-degree is a measure that indicates all outgoing relations of a user.

Contribution Behavior: As an indicator for submission behavior we used the aggregated measure contribution as it best describes the users' direct 
contribution to the challenge. Contribution is consisting of the number of contributions submitted within the research phase, number of ideas submitted within the ideas phase and number of stories written within the impact phase.

Further comparisons of clusters are conducted along the measure of betweenness and the quality of submitted ideas. Betweenness is a strong measure indicating the role of a user in the network as it describes the extent to which a particular individual lies between various other individuals in the network [40]. We considered ideas voted into the refinement phase as high quality ideas.

\section{Results}

\subsection{Descriptive Statistics and Social Network Analysis}

Figure 1 visualizes the sociogram of the social network based on the commenting behavior of users throughout the whole challenge.

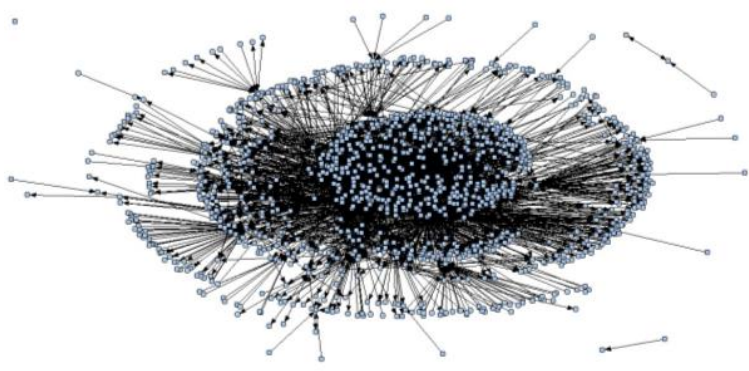

Figure 1. Overall network of the amplify community

The dyad reciprocity within the network is 44 percent. A dyad can be described as a present connection between two actors [40]. The measure is computed by comparing the number of actual reciprocal dyads compared to the number of total dyads. A reciprocal relation is established when a relation between two actors is bilateral.

In order to identify different user roles measures of commenting behavior and submission behavior need to be considered. Table 1 shows descriptive statistics of the measures used as indicators for the participation behavior of users. 1027 users had an out-degree above 0 . An out-degree above 0 indicates that those users commented at least once another user. The average outdegree of all users, indicating the average number of posts by a user is 1.67 . The in-degree centrality reveals that 932 users received at least one comment by another user. As the value of written comments and received comments remains the same, on average each user received a total of 1.67 comments. On average each participant submitted 0.33 contributions. The median of zero indicates that a large proportion of users did neither write nor receive a comment throughout the challenge (2756). This large amount of passive users within a crowdsourcing initiative of the described size is a phenomenon known in crowdsourcing literature and in line with previous research $[28,30,31]$

\section{Table 1. Descriptive statistics}

\begin{tabular}{lrrrrrr} 
& $\mathrm{n}$ & Mean & Median & Std. Dev. & Min & Max \\
\hline In-degree & 4057 & 1.669 & 0.000 & 14.2800 & 0 & 737 \\
Out-degree & 4057 & 1.669 & 0.000 & 17.0491 & 0 & 862 \\
Contribution & 4057 & 0.33 & 0.000 & 1.100 & 0 & 23
\end{tabular}

\subsection{Cluster Analysis}

Descriptive analysis of the measures presented above reveals that the average user is not representative for the community of the Amplify Challenge, as seen in the standard deviation of each measure. This is in line with existing research that supports the need of identifying and assigning user roles to understand user behavior in online communities [30, 31, 36, 41].

Therefore we applied a cluster analysis based on the three measures identified representing commenting behavior (in-degree and out-degree) and submission behavior (contribution). Values have been standardized in order to work with. In a first step we filtered community managers and a fake account created by openIDEO to preserve the content from deleted user profiles. In addition only users with either an out-degree above zero or contribution above zero were included in the cluster analysis as they are the users who actively participated. We identified two individual users who are superior in all three measures compared to the other participants. Those users were also removed from the dataset and analyzed separately in order to foster the stability of the cluster solution.

In our research, we combined a hierarchical clustering method with a non-hierarchical clustering technique [37]. As a starting point, we conducted a hierarchical clustering using the Ward minimum variance method based on squared Euclidian distances [42] to identify the number of clusters the dataset should be divided into. Interpreting the results with the help of the elbow method revealed that more than one large jump in the coefficient exist, which is evidence for more than one natural set of clusters [43]. The hierarchical cluster analysis led to the support of $2,3,4,7,8$ or 9 cluster solutions which serves as a starting point for the k-means non-hierarchical clustering method. For each case we conducted a k-means clustering analysis searching for the best cluster size. Based on the outcome of each cluster solution, the usability for interpretation 
and due to a low number of iterations needed to process the cluster analysis, a 4 cluster solution was found to be most relevant, presented in figure 2 .

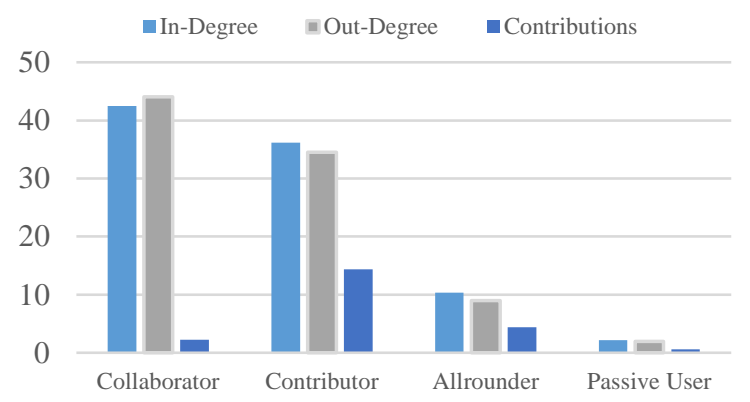

Figure 2. Four cluster solution

Labelling the different clusters was done by interpreting each cluster in detail. Table 2 shows mean values of the three measures used for each cluster solution and an overview about the distribution of users across the four clusters.

Table 2. Statistical indicators of cluster solutions

\begin{tabular}{lrrrrr} 
& $\begin{array}{c}\text { Collaborat } \\
\text { or }\end{array}$ & $\begin{array}{c}\text { Contributo } \\
\text { r }\end{array}$ & $\begin{array}{c}\text { Allrounde } \\
\text { r }\end{array}$ & $\begin{array}{c}\text { Passiv } \\
\text { e User }\end{array}$ & Total \\
\hline Variable & \multicolumn{1}{c}{ Mean } & \multicolumn{1}{c}{ Mean } & \multicolumn{1}{c}{ Mean } & Mean & \\
\hline In-Degree & 42.462 & 36.167 & 10.343 & 2.157 & \\
Out-Degree & 44.038 & 34.500 & 8.990 & 1.985 & \\
Contributions & 2.27 & 14.33 & 4.40 & 0.56 & \\
Frequency & 26 & 6 & 105 & 1164 & 1301 \\
& & & & & 100. \\
Percentage & 2.0 & 0.5 & 8.1 & 89.5 & 0
\end{tabular}

To analyze differences in these four user roles and their interaction behavior in the following each cluster will be analyzed in detail with the help of network measures and the visualization of the egocentric networks of the user roles.

Collaborator: This type of user is characterized by a very high level of commenting behavior and a very low level of contribution behavior. On average the collaborator has an in-degree of 42.46 and an out-degree of 44.04 indicating that this user is very involved in commenting and in a dialogue with other users in general, as they receive a high amount of response. At the same time the collaborator only contributes at a very low level of own contributions $(n=2.27)$ instead he is focusing on the ideas of others. Figure 3 shows the egocentric network of a typical collaborator.

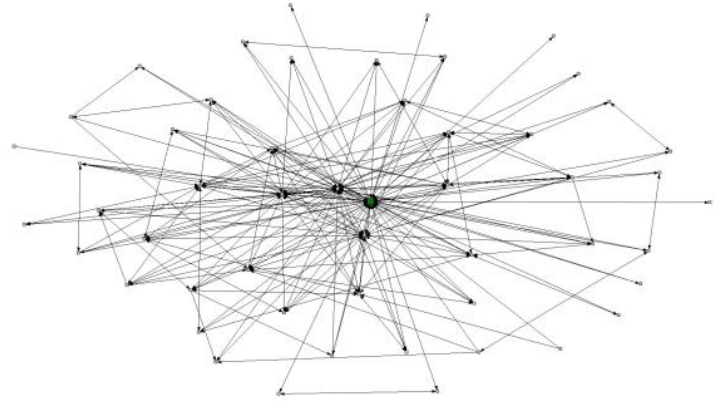

Figure 3. Collaborator (ID 24711), 3 contributions, in-degree 55, out-degree 47

Contributor: The contributor is characterized by a high level of commenting behavior and a high level of contribution behavior. In detail this type of users has on average an in-degree of 36.17 and an out-degree of 34.5. Again both commenting behavior measures are around the same value which indicates an equal distribution of ingoing and outgoing relations of a user. The egocentric network of a contributor is visualized in figure 4 . In contrast to the collaborator the contributor has a high level of contributions submitted. On average each contributor is responsible for 14.33 contributions.

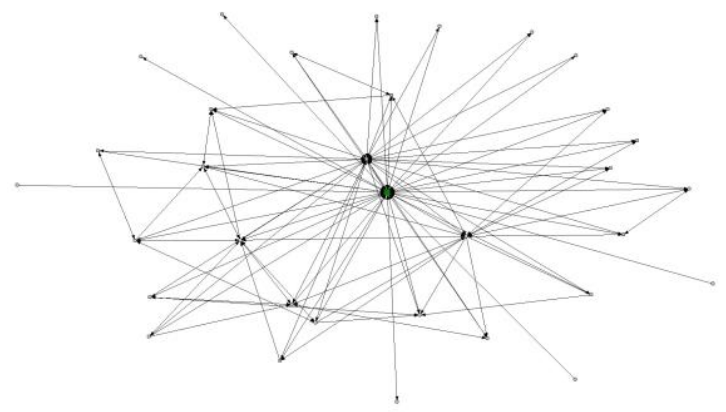

Figure 4. Contributor (ID 37383), 23 contributions, in-degree 43, out-degree 31

Allrounder: This type of user is classified with a moderate level of commenting behavior. On average an allrounder has 10.34 ingoing relations and 8.99 outgoing relations. The allrounder contributes on average 4.4 times. Compared to the previously described user roles the allrounder is low in commenting behavior. Contribution behavior positions this user above the collaborator with twice as many contributions, but way below the contributor. The commenting behavior is presented in figure 5 . 


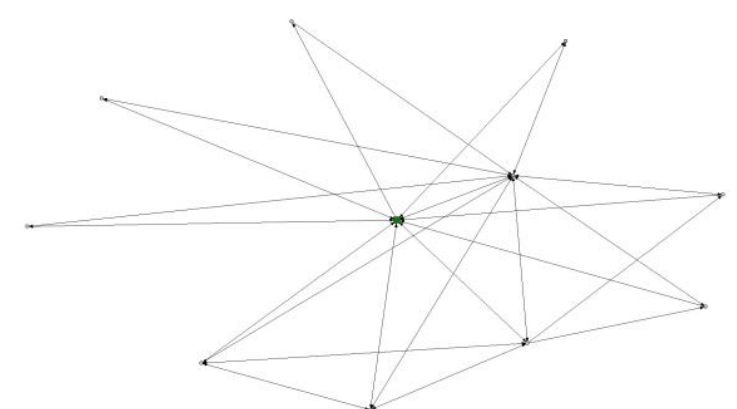

Figure 5. Allrounder (ID 39299), 6 contributions, in-degree 10, out-degree 10

Passive User: The least interactive user based on commenting behavior and submitted contributions is the passive user. On average this user type has an in-degree of 2.16 and an out-degree of 1.99. This very low commenting behavior is complemented by 0.56 contributions submitted.

In addition to these four cluster solutions we identified two high performing individuals who are superior in commenting behavior and contribution behavior. These users outperform any of the clusters and therefore they have to be approached seperatly. In our research these users are referred to as Stars.

User 23241 has an out-degree of 391 and an indegree of 220 and submitted 10 contributions. Considering his superior level of commenting behavior his importance to the interaction within the community is clearly given. His dense interaction behavior is shown in the egocentric network in figure 6.

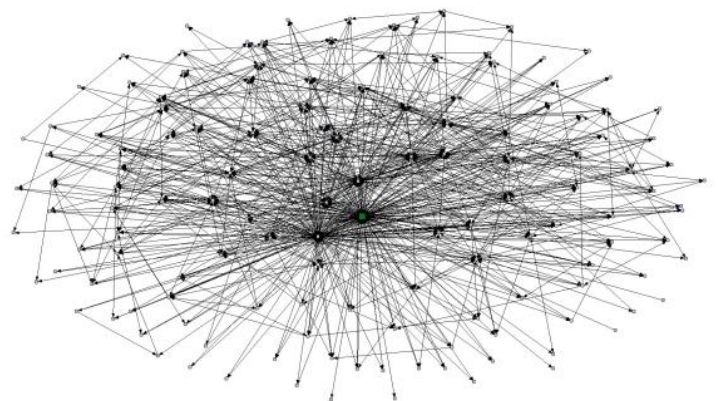

Figure 6. Star (ID 23241), 10 contributions, in-degree 220, out-degree 391
User 36885 can also be perceived as Star, as he has an in-degree of 125, an out-degree of 144 and submitted 9 contributions. These values implicate that this user contributes to the community with both, his interaction behavior and contribution behavior with a strong focus on interaction (Figure 7).

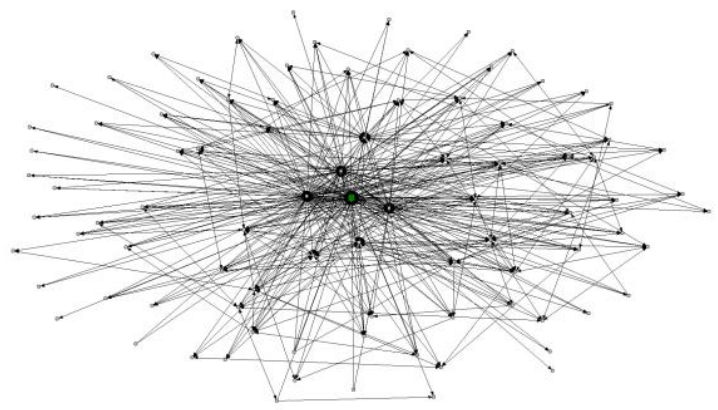

Figure 7. Star (ID 36885), 9 contributions, in-degree 125, out-degree 144

\subsection{Comparing Quality of Contribution across User Roles}

In a next step we compared the quality of submitted contributions across the identified user roles. Out of 575 ideas, 52 were selected for the refinement phase. A dichotomous variable was calculated (" 1 " if a submitted idea reached the refinement phase; " 0 " if the submitted idea did not reach the refinement phase). An ANOVA revealed that the collaborators differ significantly in terms of quality of ideas submitted compared to the other three user roles. As table 3 shows the collaborator submitted most ideas which managed to get to the refinement phase with a mean value of 0.46 . This means the collaborator submits ideas with the highest potential to be of high quality. With a probability of 46 percent an idea submitted by a collaborator is elected to the refinement phase.

\subsection{Comparing Structural Position across User Roles}

As a last step we study how the identified user roles differ in terms of structural position. We therefore compare the network measure betweenness across the

Table 3. Idea quality and betweenness among user roles

\begin{tabular}{|c|c|c|c|c|c|c|c|c|c|c|}
\hline & \multicolumn{2}{|c|}{ Collaborator } & \multicolumn{2}{|c|}{ Contributor } & \multicolumn{2}{|c|}{ Allrounder } & \multicolumn{3}{|c|}{ Passive User } & \multirow[b]{2}{*}{ F-Value } \\
\hline Variable & Mean & SD & Mean & SD & Mean & SD & Mean & SD & Total & \\
\hline Idea Quality: Refinement Phase & 0.46 & 0.508 & 0.17 & 0.408 & 0.04 & 0.192 & 0.03 & 0.168 & & $47.507 * * *$ \\
\hline Structural Position: Betweenness & 18265.95 & 17708.01 & 7430.90 & 3832.72 & 1749.53 & 3293.32 & 333.47 & 1398.56 & & $326.342 * * *$ \\
\hline $\mathrm{n}$ & 26 & & 105 & & 105 & & 1164 & & 1301 & \\
\hline Percentage & 2.0 & & 0.5 & & 8.1 & & 89.5 & & 100 & \\
\hline
\end{tabular}

Notes: Refinement Phase: $0=$ lowest score; $1=$ best score. $* p<0.05 ; * * p<0.01 ; * * * p<0.001$ 
four user roles. Due to the fact that users with a high degree do not necessarily have to play an important intermediary role this measure is crucial to get a deep understanding of the network [44].

ANOVA revealed that the betweenness differs significantly across all four user roles. All means and standard deviations can be seen in table 3. A high betweenness, as seen on the collaborator, indicates a strong dependency of others on the observed user who can be seen as gatekeeper [44].

\section{Discussion and Implications}

In this exploratory study, we examined the community structures of an open development model in form of a crowdsourcing initiative that aims to find social innovation to enhance the condition of a lowincome community. The investigated community (openIDEO.org) represents a social network defined by actor to actor relationships. By using network measures (in-degree, out-degree, betweenness, reciprocity) and users' contribution quantity and quality this study elaborates insights in the network structure and users' roles and behaviors on the platform.

On the community perspective, findings reveal that a large number of participants are passive users. This reflects findings of previous research on crowdsourcing communities [28, 30, 31]. In addition this research discovered a high level of interaction between all active users. All users who actively engage in the community show a very intense interaction behavior, expressed by high levels of in-degree and out-degree. Saliently, the in-degree and out-degree are of similar level. This indicates a high collaboration between users and reciprocal conversations, as users not only write a high amount of comments, but in return also receive roughly the same amount of comments. The finding is supported by a high dyad reciprocity of the network of 44 percent compared to the dyad reciprocity in an innovation contest of around 10 percent [45]. Hence it can be assumed that the social purpose leads to a high collaboration in the community, which is in line with literature stating that doing something good is supposed to minimize competition [8], but should lead to open collaboration and meaningful dialogue [8]. As social entrepreneurs are supposed to be driven by altruism and the urge to achieve social goals rather than focusing on personal gain [17], it can be argued that the overall communication pattern in the investigated community is an indicator for the behavioral pattern of social entrepreneurs.

A key contribution of this study is the identification of four distinct user roles within the investigated community, namely collaborators, contributors, allrounders, passive users. Those user roles display significant difference in terms of interaction behavior and contribution behavior. Getting a clear picture of how users behave within such a crowdsourcing community represents an important insight for organizers to successfully manage the community and foster social innovation.

The collaborators have been identified as the most interactive user role. This type of user seems to be able to integrate his/her collected knowledge into his/her ideas, as he submits ideas with the highest potential to be of high quality. In addition, this type of user is able to transfer knowledge between lots of other users giving this user a gatekeeper position in the network. Without such gatekeepers the community loses a lot of knowledge and may have a deficit in collective intelligence [27]. A similar user role could not be found in existing literature. We assume the collaborators unique behavioral patterns strongly relate to the social context of the community. Based on the definition of social entrepreneurs, we presume a high number of social entrepreneurs in the cluster of the collaborator. The contributor attracts attention in being good in all disciplines. They are of special value for the community as a high amount of submitted ideas increases the probability of finding an appropriate solution [46]. The contributors can be compared to the user role insiders, identified by Kozinets [28], and masters, as described by Füller [31]. The relatively large group of allrounders interact and submit ideas at a moderate level with a balanced ingoing and outgoing commenting behavior. However, the majority of users are represented by passive users.-Furthermore we discovered star users within the community, who are fairly superior in all disciplines. But also here the pattern of both sided interaction can be seen. We couldn't find a user type focused only on contributions as mentioned in Füller [31]. Most active users participate in a dialogue within the community of our study.

Our results have important theoretical and practical implications as they indeed show that the behavior of users in the investigated context differs significantly in terms of interaction behavior compared to other crowdsourcing initiatives. The presented findings contribute to a better understanding of the dynamics and structures of crowdsourcing communities search for social innovation. We contribute to the theory of crowdsourcing by illustrating that context and purpose of crowdsourcing initiatives may impact the behavior [13] and type of users [12]. Further we add insights to the linkage between crowdsourcing and social innovation [19] in the context of open development [5].

The results can aid designers and organizers to appropriately structure crowdsourcing initiatives that permit and intensify dialogue. Community managers 
can utilize the information to adjust their moderation strategies and strengthen bonds between users and encourage participation.

\section{Conclusion}

We consider crowdsourcing as promising open model to integrate large networks into the innovation process and increase the potential of social innovation. We have shown that different user roles with different interaction and contribution behavior exist within crowdsourcing communities in the specific context of crowdsourcing social innovation

The generalizability of this research has to be questioned as it is the first study focusing on user roles in the area of open development communities. With over 4000 observed participants this study can be considered as the current best practice example but needs to be proven by analyzing more crowdsourcing initiatives in the same specific setting. The research focused on an exploratory design with emphasis on interaction and contribution behavior which may be complemented by additional measures indicating the growth of user roles throughout the crowdsourcing initiative in future research. Also, this paper used a quantitative research approach accomplished with a SNA. Future studies need to include qualitative content analysis regarding comments and submitted ideas to strengthen and further develop the presented user roles.

\section{Acknowledgements}

We would like to thank the Amplify Team and openIDEO for supporting us in gathering the data for this study. We are also grateful to the vice rector of research at the University of Innsbruck for the provision of funding to Simon Fuger ("Doktoratsstipendium aus der Nachwuchsförderung”).

\section{References}

[1] Murray, R., J. Caulier-Grice, and G. Mulgan, The open book of social innovation, National endowment for science, technology and the art London, 2010.

[2] Chesbrough, H.W., "The era of open innovation", MIT Sloan Management Review, Spring, 2003.

[3] Howe, J., Crowdsourcing: Why the Power of the Crowd is Driving the Future of Business, Random House Business Books, New York, 2009.

[4] Chalmers, D., "Social Innovation: An exploration of the barriers faced by innovating organisations in the social economy", Local Economy, 2012, pp. 1-18.
[5] Bentley, C.M. and A. Chib, "The Impact of Open Development Initiatives in Lower-and Middle Income Countries: A Review of the Literature", The Electronic Journal of Information Systems in Developing Countries, 74, 2016, pp. 1-20.

[6] Christensen, C.M., H. Baumann, R. Ruggles, and T.M. Sadtler, "Disruptive innovation for social change", Harvard business review, 84(12), 2006, pp. 1-8.

[7] Füller, J., G. Jawecki, and H. Mühlbacher, "Innovation creation by online basketball communities", Journal of Business Research, 60(1), 2007, pp. 60-71.

[8] Buskens, I., "Open Development Is a Freedom Song: Revealing Intent and Freeing Power", Open development: Networked innovations in international development, 2014, pp. 327-351.

[9] Cajaiba-Santana, G., "Social innovation: Moving the field forward. A conceptual framework", Technological Forecasting and Social Change, 82, 2014, pp. 42-51.

[10] Smith, M. and L. Elder, "Open ICT ecosystems transforming the developing world", Information Technologies \& International Development, 6(1), 2010, pp. 65-71.

[11] Hinds, D. and R.M. Lee, "Social network structure as a critical success condition for virtual communities", IEEE, 2008.

[12] Hautz, J., K. Hutter, J. Füller, K. Matzler, and M. Rieger, "How to establish an online innovation community? the role of users and their innovative content", Proceedings of the 43rd Hawaii International Conference on System Sciences, 2010.

[13] Nolker, R.D. and L. Zhou, "Social computing and weighting to identify member roles in online communities", IEEE, 2005.

[14] Franz, H.-W., J. Hochgerner, and J. Howaldt, Challenge social innovation: Potentials for business, social entrepreneurship, welfare and civil society, Springer Science \& Business Media, 2012.

[15] Phills, J.A., K. Deiglmeier, and D.T. Miller, "Rediscovering social innovation", Stanford Social Innovation Review, 6(4), 2008, pp. 34-43.

[16] Jankel, N., "Radical (re) invention", London: wecreate, 2011.

[17] Lettice, F. and M. Parekh, "The social innovation process: themes, challenges and implications for practice", International Journal of Technology Management, 51(1), 2010, pp. 139-158.

[18] Neumeier, S., "Why do social innovations in rural development matter and should they be considered more seriously in rural development research?-proposal for a stronger focus on social innovations in rural development research", Sociologia ruralis, 52(1), 2012, pp. 48-69. 
[19] Hoang, H. and B. Antoncic, "Network-based research in entrepreneurship: A critical review", Journal of business venturing, 18(2), 2003, pp. 165-187.

[20] Martin, R., "How successful leaders think", Harvard business review, 85(6), 2007, pp. 71-84.

[21] Reilly, K.M.A. and M.L. Smith, "The emergence of open development in a network society", Open development: Networked innovations in international development, 2013, pp. $15-50$.

[22] Smith, M.L., K.M.A. Reilly, and Y. Benkler, Open development: Networked innovations in international development, MIT Press, 2014.

[23] Füller, J., K. Hutter, and M. Fries, "Crowdsourcing for goodness sake: impact of incentive preference on contribution behavior for social innovation", Advances in International Marketing, 11(23), 2012, pp. 137-159.

[24] O'Reilly, T. and J. Battelle, Web squared: Web 2.0 five years on, O'Reilly Media, Inc., 2009.

[25] Boudreau, K.J. and K.R. Lakhani, "Using the crowd as an innovation partner", Harvard business review, 91(4), 2013, pp. 60-69.

[26] Füller, J., K. Hutter, and M. Fries, "Crowdsourcing for goodness sake: impact of incentive preference on contribution behavior for social innovation", Advances in International Marketing, 11(23), 2012, pp. 137-159.

[27] Welser, H.T., D. Cosley, G. Kossinets, A. Lin, F. Dokshin, G. Gay, and M. Smith, "Finding social roles in Wikipedia", Proceedings of the 2011 iConference, pp. 122129.

[28] Kozinets, R.V., "E-tribalized marketing?: The strategic implications of virtual communities of consumption", European Management Journal, 17(3), 1999, pp. 252-264.

[29] Malinen, S., "Understanding user participation in online communities: A systematic literature review of empirical studies", Computers in Human Behavior, 46, 2015, pp. 228238 .

[30] Koch, G., K. Hutter, P. Decarli, D. Hilgers, and J. Füller, "Identifying Participants' Roles in Open Government Platforms and Its Impact on Community Growth", 46th Hawaii International Conference on System Sciences, 2013.

[31] Füller, J., K. Hutter, J. Hautz, and K. Matzler, "User roles and contributions in innovation-contest communities", Journal of Management Information Systems, 31(1), 2014, pp. 273-308.

[32] Toral, S.L., M.d.R. Martínez-Torres, and F. Barrero, "Analysis of virtual communities supporting OSS projects using social network analysis", Information and Software Technology, 52(3), 2010, pp. 296-303.
[33] Zhao, Y. and Q. Zhu, "Evaluation on crowdsourcing research: Current status and future direction", Information Systems Frontiers, 16(3), 2014, pp. 417-434.

[34] Friemel, T.N., Why Context Matters: Applications of social network analysis., VS Verlag für Sozialwissenschaften, 9-13, Wiesbaden, 2008.

[35] Gleave, E., H.T. Welser, T.M. Lento, and M.A. Smith, "A Conceptual and Operational Definition of 'Social Role' in Online Community", Proceedings of the 42nd Hawaii International Conference on System Sciences, 2009.

[36] Hutter, K., J. Hautz, J. Füller, J. Mueller, and K. Matzler, "Communitition: the Tension between competition and collaboration in community-based design contests", Creativity and Innovation Management, 20(1), 2011, pp. 321.

[37] Punj, G. and D.W. Stewart, "Cluster analysis in marketing research: Review and suggestions for application", Journal of marketing research, 1983, pp. 134-148.

[38] Cormack, R.M., "A review of classification", Journal of the Royal Statistical Society. Series A (General), 1971, pp. 321-367.

[39] Kratzer, J. and C. Lettl, "A social network perspective of lead users and creativity: An empirical study among children", Creativity and Innovation Management, 17(1), 2008, pp. 26-36.

[40] Borgatti, S.P., M.G. Everett, and J.C. Johnson, Analyzing social networks, SAGE Publications Limited, 2013.

[41] Panzarasa, P., T. Opsahl, and K.M. Carley, "Patterns and dynamics of users' behavior and interaction: Network analysis of an online community", Journal of the American Society for Information Science and Technology, 60(5), 2009, pp. 911-932.

[42] Ward Jr, J.H., "Hierarchical grouping to optimize an objective function", Journal of the American statistical association, 58(301), 1963, pp. 236-244.

[43] Ketchen, D.J. and C.L. Shook, "The application of cluster analysis in strategic management research: an analysis and critique", Strategic management journal, 17(6), 1996, pp. 441-458.

[44] Scott, J., Social network analysis, Sage, London, 2012.

[45] Kathan, W., J. Füller, and K. Hutter, "Reciprocity in innovation contest communities reciprocity vs. free-riding in an environment of competition", Creativity and Innovation Management, 2013, pp. 537-549.

[46] Osborn, A.F., Applied imagination, Scribner's, Oxford UK, 1953. 